\title{
SURFACE EFFECTS ON LOW CYCLE FATIGUE BEHAVIOR IN IN718 ALLOY
}

\author{
Prabir R. Bhowal ${ }^{1}$, Darryl Stolz ${ }^{1}$, Agnieszka M. Wusatowska-Sarnek ${ }^{1}$, Rick Montero ${ }^{1}$ \\ ${ }^{1}$ Pratt \& Whitney; 400 Main Str.; M/S 114-40; East Hartford, CT 06108, USA
}

Keywords: IN718, Direct Aged, Machining, Low Cycle Fatigue, Carbides

\begin{abstract}
Superalloys used in gas turbine engine rotating components require superior low cycle fatigue (LCF) properties, but often, the intrinsic LCF capability of the rotor, as determined by laboratory specimen tests, is limited by presence of fine particles such as carbides, borides and ceramic inclusions, as well as, pores, voids, and large grains in the alloy. Further, manufacturing processes such as turning, milling, and broaching can limit LCF life if they introduce surface damage and/or tensile residual stress. In IN718, prior studies have shown that fatigue initiation from MC carbides is promoted at lower test temperature and high stress, and the LCF life is significantly reduced. The present study investigates the effect of machining that can introduce carbide damage on LCF life, and a few post-machine processing methods for LCF recovery.

The IN718 material used in this study came from a gas turbine disk forging that was directly aged without the conventional solution heat-treatment. The microstructure was fine-grained with an average grain size of $11 \mu \mathrm{m}$. Smooth and notched LCF properties were evaluated with machined and polished surfaces at test temperature and stress that promoted carbide initiation of fatigue cracks. Majority of the tests were performed at temperature of $560 \mathrm{~K}$ and at stresses of 1102 and $1240 \mathrm{MPa}$ for smooth, and nominal stresses of 595 and $650 \mathrm{MPa}$ for notched specimens. The min to max stress ratio $(\mathrm{R})$ was 0.05 . The cycles to failure were analyzed in terms of machining effect on surface carbides, and the fatigue initiation sites were studied by scanning electron microscopy (SEM). Smooth LCF specimens included asmachined (lathe-turned) and polished (600 grit $\mathrm{SiC}$ ) surfaces and the notched LCF specimens included single-point bored (SPB) and media-polished notch surfaces. Lathe-turning and SPB cracked or damaged surface and subsurface carbides, considerably impacting the LCF life by factors of 3-15X (depending on test conditions). For a smooth lathe-turned surface, shot peening was effective in recovering LCF life by $5-10 \mathrm{X}$ at minimum over the as-machined surface. Some conventional post-machine processes for holes, such as mechanical honing, extrude hone and jig grinding and their influence on LCF life were studied as well.
\end{abstract}

\section{Introduction}

Inconel 718 (IN718) is a Ni-based superalloy that is widely used to manufacture rotating components in gas turbine engines due to its high strength and good low cycle fatigue (LCF) resistance [1, 2]. This alloy is used most commonly in the solution heat treatment plus aged condition. Strength and LCF properties are critical in gas turbine applications, and in situations requiring enhanced properties, a 'direct aged' version without the solution treatment is used. The present study relates to the 'direct aged' version of the alloy. In this version, the gas turbine disk is typically produced by 'hot-die' forging followed by aging. Grain refinement during forging is critical in this process for improved LCF life of the disk $[3,4]$. It is desirable that the fatigue critical disks are produced with a fine grained microstructure in the range of 5-20 $\mu \mathrm{m}$ to maximize fatigue benefits. However, prior studies have shown that crack initiation at carbides is promoted at high stress amplitude [5] and also, at lower test temperatures [6], and therefore, the carbides might limit the benefits from grain refinement under certain conditions. Further, the carbides at the surface of the part are sensitive to damage from surface machining $[7,8]$ or surface treatment processing, and in such cases, cracks may initiate early from carbides $[9,10]$. The purpose of the present study is thus aimed at understanding the carbide damage produced during machining, and their effect on smooth and notched LCF life in 'direct aged' IN718 rotor material. Further, conventional post-machine processing of the surface was examined in terms on carbide damage and LCF life.

\section{Material and Experimental Procedure}

Rotor grade ‘direct aged’ IN718 (DA718) disks were produced by commercial 'hot-die' forging practice into a contoured shape. The disk represented a forging shape for a large diameter but thin cross-section gas turbine engine with outer and inner (bore) diameters of $900 \mathrm{~mm}$ and $480 \mathrm{~mm}$, respectively, and outer rim thickness of $63 \mathrm{~mm}$. The input stock for the forgings was commercially available $250 \mathrm{~mm}$ diameter billet material produced from triple-melted (VIM+ESR+VAR) ingot. The wt. \% chemistry of the billet was $18.0 \% \mathrm{Cr}, 2.96 \% \mathrm{Mo}, 1.0 \% \mathrm{Ti}, 0.50 \%$ $\mathrm{Al}, 5.4 \% \mathrm{Nb}+\mathrm{Ta}(\mathrm{Ta}<0.01), 17.95 \% \mathrm{Fe}, 0.028 \% \mathrm{C}$, and balance $\mathrm{Ni}$. The forging was given the standard IN718 aging cycle consisting of $990 \mathrm{~K}$ for 8 hours, followed by $895 \mathrm{~K}$ for 8 hours.

For the study of surface effects on LCF life, two types of conventional machining, namely, lathe-turning (LT) for flat surfaces and single point boring (SPB) for round holes, were used. Post-machine processing was used for round holes following SPB to determine its effect on LCF life. Processes evaluated were: mechanical honing with 400 grit $\mathrm{SiC}$ tools [11], extrude hone with 54 grit SiC abrasive media [12], and jig grinding with carbide tools [13]. Mechanical honing relies on simultaneous rotating and reciprocating motion of a stone or stick, made of bonded abrasive, to remove stock material in a low speed sizing operation. During an extrude-hone operation, a semisolid media embedded with abrasive grit is extruded between cylinders on either end of the work piece to remove stock material. Jig grinding is a form of internal grinding for finishing of the internal diameter of a part. For the flat surfaces, no such post-machine processing was applied, except that the effect of compressive residual stresses from 4A shot-peening was examined in terms of LCF effect.

Both flat and cylindrical test specimens were used for smooth LCF tests. The flat specimens had a rectangular gage section of nominal dimensions $50 \mathrm{~mm} \times 12 \mathrm{~mm} \times 5 \mathrm{~mm}$, and the flat surfaces represented the lathe-turned surface of conventional IN718 disk machining. The edges of the specimen were polished and the grips shot-peened. An example of the flat specimen with lathe-turned surface is shown in Fig. 1A. Cylindrical specimens 
were used for reference LCF test with polished surface (per ASTM E606). An example of the specimen is shown in Fig. 1B. Approximately, 25 micron of surface material was removed using 400 and 600 grit SiC polishing. The nominal gage dimensions of the specimen were $25 \mathrm{~mm}$ long x $9.4 \mathrm{~mm}$ diameter. For notched LCF, the specimen was flat with a central and through thickness hole. The gage section was rectangular with nominal dimensions of $38 \mathrm{~mm}$ x $37 \mathrm{~mm} \times 3.7 \mathrm{~mm}$. The central hole produced a stress concentration $\left(\mathrm{K}_{\mathrm{t}}\right)$ of about 2.5 during axial LCF loading of the specimen. An example of the specimen is shown in Fig. 1C. The hole was machined by single-point boring (SPB) that left machining marks parallel to the stress axis. For reference tests, the same notched specimen was used but the central hole was 'mediafinished'. For media finishing, medium-sized-fused-cast $\mathrm{Al}_{2} \mathrm{O}_{3}$ granules were used.

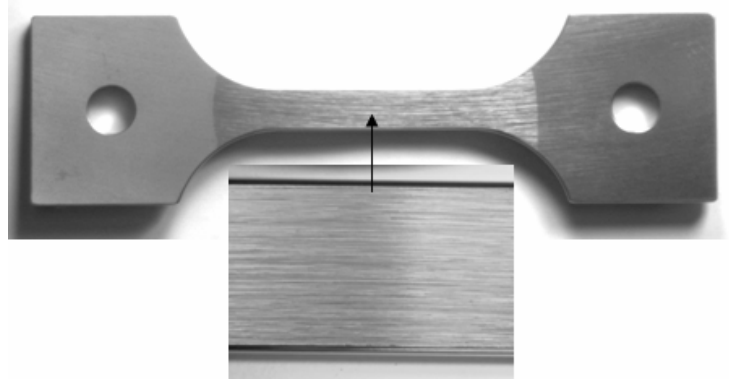

(A)

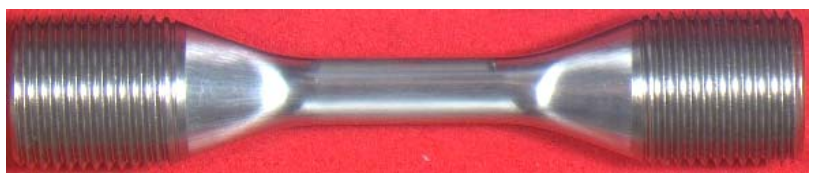

(B)

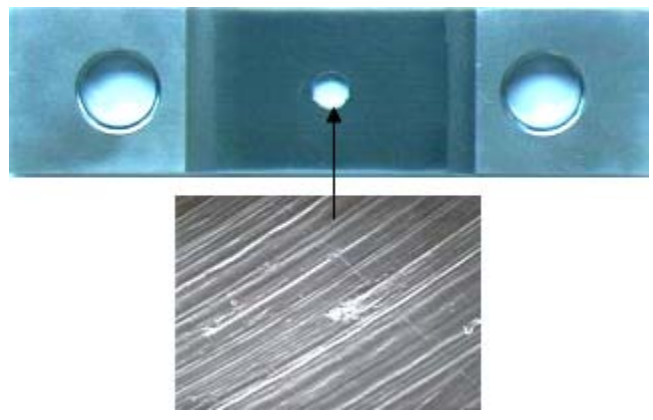

(C)

Figure 1. Example of smooth and notched LCF specimens with (A) lathe-turned gage section, (B) polished gage section, and (C) notched gage section with central hole (shown are machining marks left after single-point boring).

The LCF tests were carried out initially at several temperatures from $300 \mathrm{~K}$ to $880 \mathrm{~K}$. It was determined that an intermediate temperature of $560 \mathrm{~K}$ adequately defined the LCF sensitivity to surface condition, and therefore, the majority of tests were carried out at 560K. Axial stresses of 1102 and $1240 \mathrm{MPa}$ were used for smooth LCF tests, and 595 and $650 \mathrm{MPa}$ nominal for notched LCF tests (1516 and $1656 \mathrm{MPa}$ concentrated stresses at the notch root, respectively). Tests were performed in a modified MTS servo-hydraulic machine using sinusoidal waveform and a min to max stress ratio (R) of 0.05 , and test frequency of $1 \mathrm{~Hz}$. The LCF crack initiation sites of fractured specimens were studied by scanning electron microscopy (SEM) equipped with energy dispersive X-ray spectroscopy (EDS). It should be noted that in presenting the LCF lives in this paper, a relative scale was used, namely, in each Figure, the lowest LCF life of all data presented in this paper was indexed as 100, and all other lives were expressed as multiples of this lowest LCF life.

\section{Results and Discussion}

\section{Microstructure and Tensile Properties}

The microstructure of the forged and direct aged disk is shown in Fig. 2. The average gamma $(\gamma)$ grain size was $11 \mu \mathrm{m}$ (ASTM 10) with grain size varying from $5.6 \mu \mathrm{m}$ to $16 \mu \mathrm{m}$ (ASTM 9-12) depending on the location in the disk. Occasional grains with sizes as large as 20 to $30 \mu \mathrm{m}$ (ASTM 7-8) were also observed but they represented a small area fraction $(<2 \%)$ in the microstructure. Further, the microstructure contained $\mathrm{Nb} / \mathrm{Ti}$-rich MC carbides, spherodized delta-phase $\left(\delta: \mathrm{Ni}_{3} \mathrm{Nb}\right)$, and two strengthening phases: $\gamma^{\prime}$ and $\gamma^{\prime}$ precipitates [14]. The MC carbides were the most important constituents that reacted severely to tool tip cutting edges and produced surface damages. Therefore, maximum carbide size, the frequency of their occurrence and their clustering tendency are critical to the understanding of LCF capability. In the DA718 material studied here, the largest carbides were typically $20-25 \mu \mathrm{m}$ in equivalent diameter.

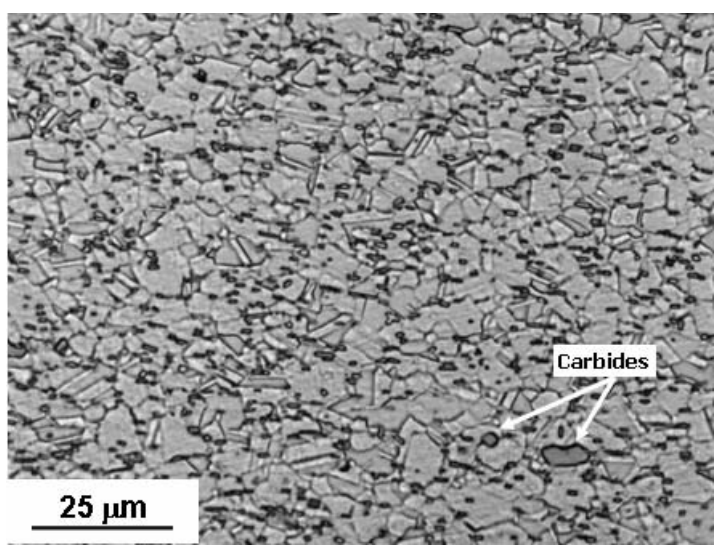

Figure 2. Example of microstructure. The carbides shown in the micrograph is of MC type.

The typical tensile properties of the disk forging are given in Table I. The 'direct aged' disk of the present study represented higher $0.2 \%$ yield strength (approximately, $15 \%$ ) relative to the conventional solution plus aged disk material.

Table I: Typical tensile properties of the disk forging

\begin{tabular}{cccc}
\hline Temperature $(\mathrm{K})$ & $\sigma \mathrm{Y}(\mathrm{MPa})$ & $\sigma \mathrm{UTS}(\mathrm{MPa})$ & $\varepsilon_{\mathrm{f}}(\%)$ \\
\hline 298 & 1340 & 1550 & 15 \\
561 & 1276 & 1375 & 16 \\
811 & 1232 & 1366 & 16 \\
921 & 1174 & 1316 & 23 \\
\hline
\end{tabular}


Surface Observations Following Conventional Machining and Effect on Low Cycle Fatigue Properties

As noted earlier, two types of conventional machining (latheturning and single point boring) were initially studied in terms of surface effects of LCF life. Fig. 3A and 3B show examples of surface appearances following lathe-turning of flat surfaces and single point boring of round holes, respectively. The critical damages on the surface, as shown in Fig. 3, were produced by the tool tip interacting with the MC carbides. The NbC was the most numerous of the MC carbides followed by $\mathrm{Nb}(\mathrm{Ti}) \mathrm{C}$, and these carbides were cracked by the tool tip, and sometimes pulled out of the surface in fragments, and dragged along the surface in the direction of the tool tip motion.

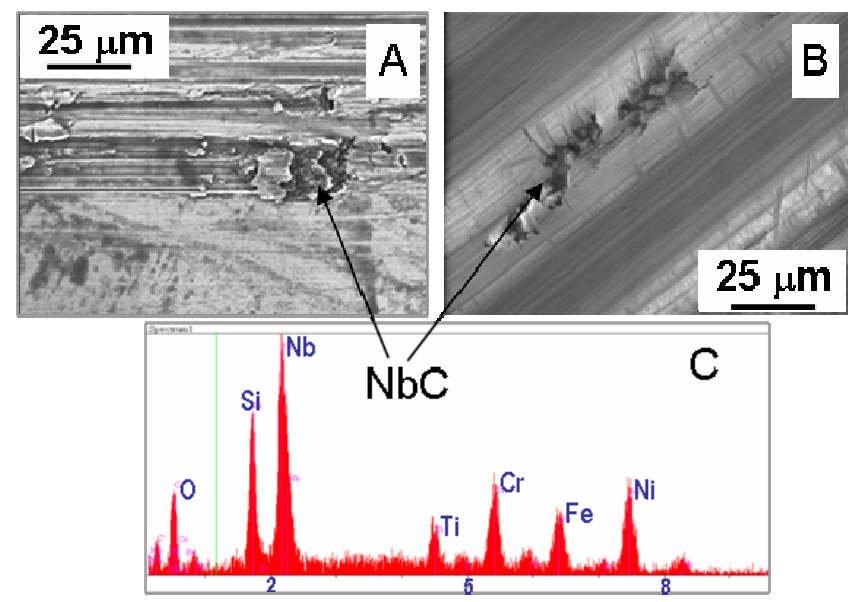

Figure 3. Examples of surface NbC carbide and surface damage during (A) lathe-turning (LT) of flat surface, and (B) single point boring (SPB) of round hole.

Cracking of MC carbides at the surface was further examined on unetched polished cross sections. Figure 4 shows evidence of carbide cracking at surface and subsurface locations typically within $25 \mu \mathrm{m}$ of the machined surfaces. On the other hand, the post-machine polishing showed that the MC carbides generally remained uncracked, and only rare evidence of large carbides with light traces of cracking was observed. Examples of unetched cross sections through polished surfaces are shown in Figure 5.

As-Machined Surface Effect on LCF. The effect of the asmachined surface on smooth LCF life is shown in Fig. 6 in relation to reference LCF specimens that had a polished surface. The abscissa axis is a relative scale for LCF lives, and data are shown for tests at low and high stresses (1102 and $1240 \mathrm{MPa}$ ) for a test temperature of $560 \mathrm{~K}$. A significant drop in LCF life, approximately, $15 \mathrm{X}$ at $1102 \mathrm{MPa}$ and $3 \mathrm{X}$ at $1240 \mathrm{MPa}$, was evident from the machined surfaces relative to the polished surfaces. Similar observations were also made with the notched LCF specimens for tests at the same temperature, and nominal stresses of 595 and $650 \mathrm{MPa}$. Figure 7 shows test results, and a drop in LCF life by about $6 \mathrm{X}$ at $595 \mathrm{MPa}$ and $4 \mathrm{X}$ at $650 \mathrm{MPa}$ was evident due to the machined surfaces relative to the polished surfaces. Methods of removing stock material (i.e. polishing) without damaging the surface carbides were demonstrated to be effective at improving the LCF life compared to conventionally machined surfaces.
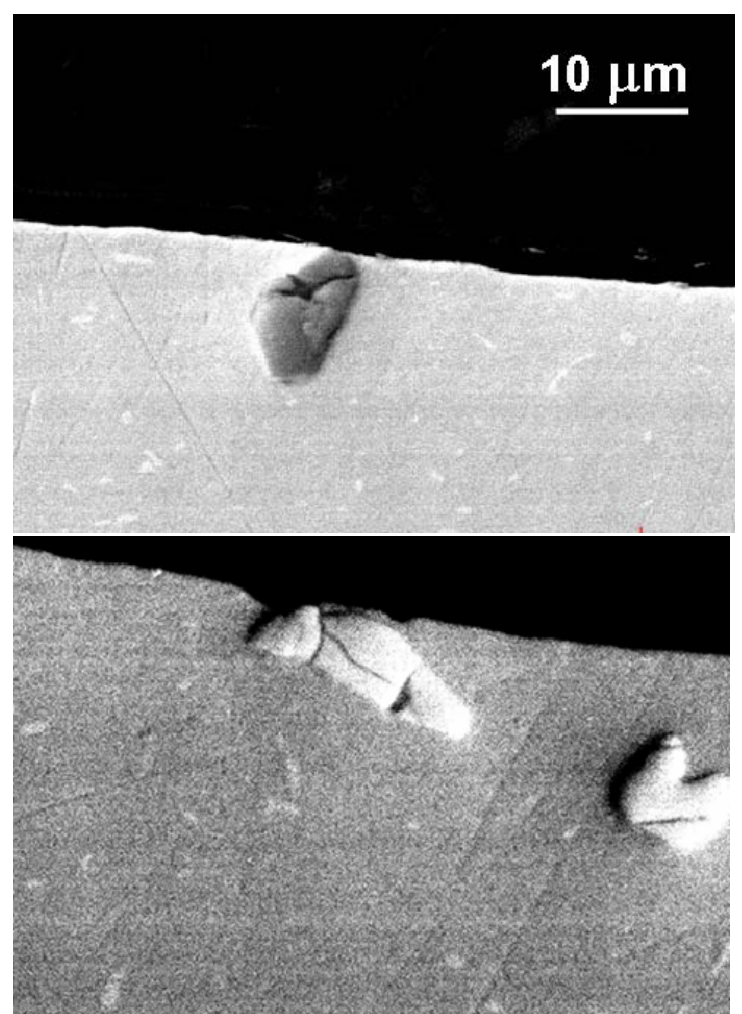

Figure 4. Unetched micrograph from section through machined surface illustrating cracked carbides at surface and subsurface locations.
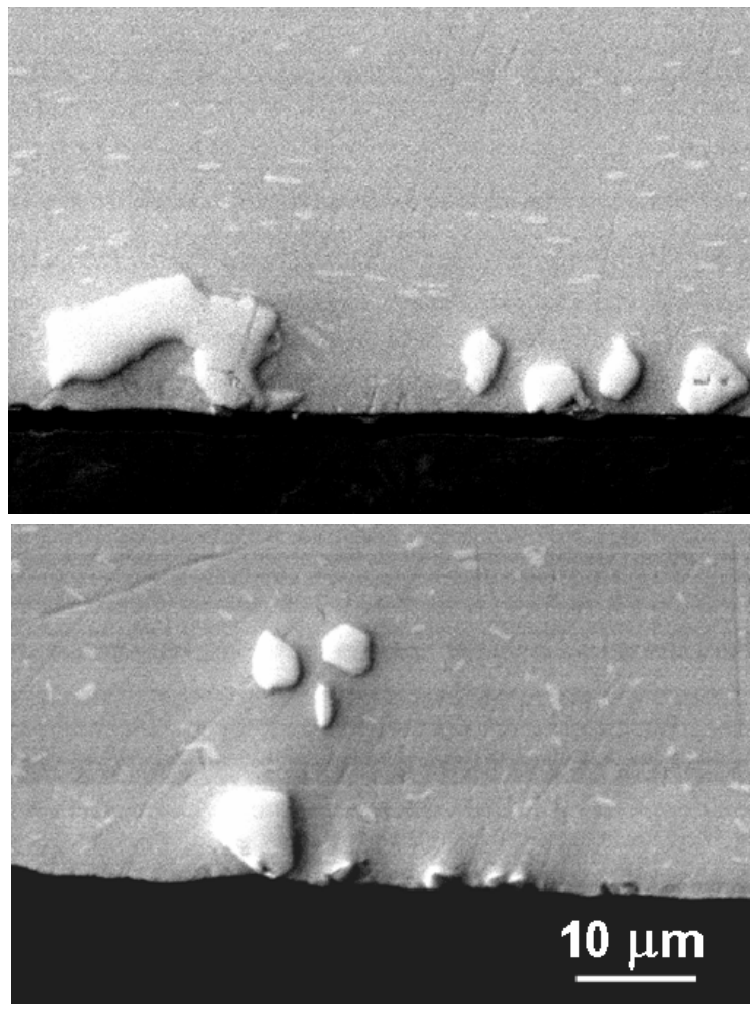

Figure 5. Unetched micrograph from section through postmachine polished surface illustrating predominantly undamaged carbides at surface and subsurface locations. 


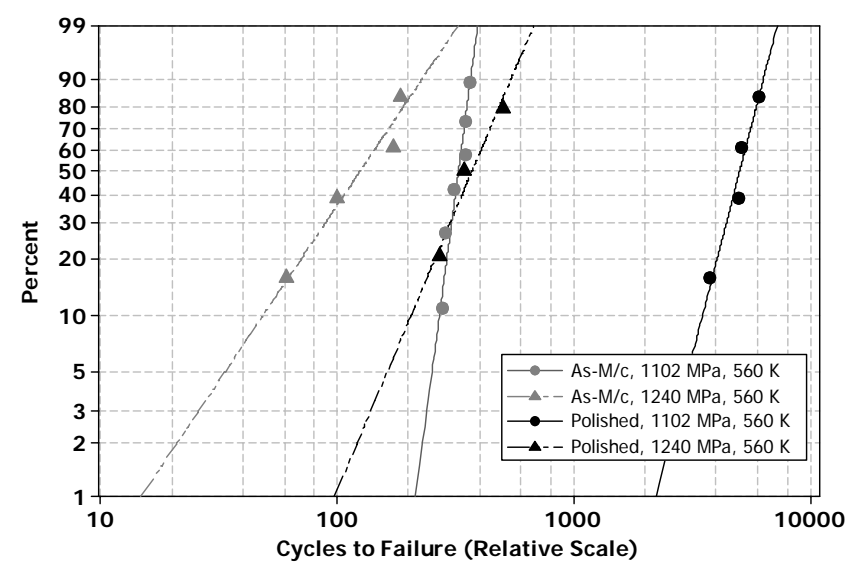

Figure 6. Weibull plot showing effect of as-machined surface on smooth LCF life relative to polished surface. Test temperature $560 \mathrm{~K}$, and applied stresses 1102 and $1240 \mathrm{MPa}$.

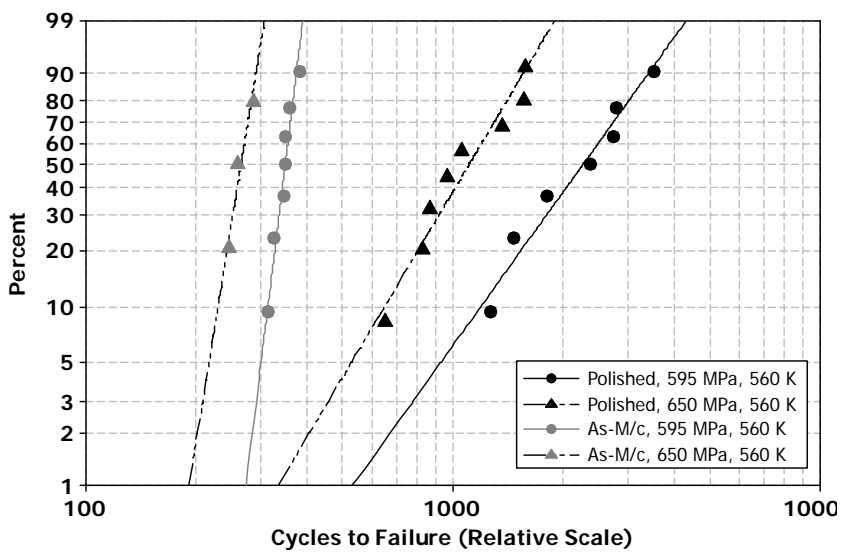

Figure 7. Weibull plot showing effect of as-machined surface (SPB) on notched LCF life relative to media-polished surface. Test temperature $560 \mathrm{~K}$, and applied nominal stresses 595 and $650 \mathrm{MPa}$.

LCF Initiation Sites. The carbides were most life limiting for the $560 \mathrm{~K}$ tests. The LCF failure in the as-machined specimens always initiated from surface MC carbides (primarily $\mathrm{NbC}$ ) due to frequent cracking of these carbides from the machining operation. Figure 8 shows SEM micrographs illustrating a damaged $\mathrm{NbC}$ on the machined surface, and the LCF initiation from such carbides in smooth LCF specimens. The typical size of the carbide at the initiation site ranged from 15 to $25 \mu \mathrm{m}$ and corresponded to the large carbides in the size distribution. Many secondary cracks were present on the specimen surface, and were always associated with carbides as shown in Fig. 8A. These micro-cracks formed early in life [6] especially under conditions of high stress amplitude. Their presence suggests that the carbides, when damaged or cracked by the insert tip during machining, caused early LCF initiation and led to significant life reduction relative to polished specimens. In the polished LCF specimens, the $560 \mathrm{~K}$ tests included both carbide and grain initiations, which were located at both surface and subsurface locations. Figure 9 shows SEM fractographs of LCF initiation from an as-machined (SPB) notched LCF specimen. LCF failure always initiated from surface carbide that was damaged or cracked by the tool tip. In the notched specimen, the highest stress occurred only at the notch root, and secondary cracks were thus infrequent and limited to the notch root vicinity only.
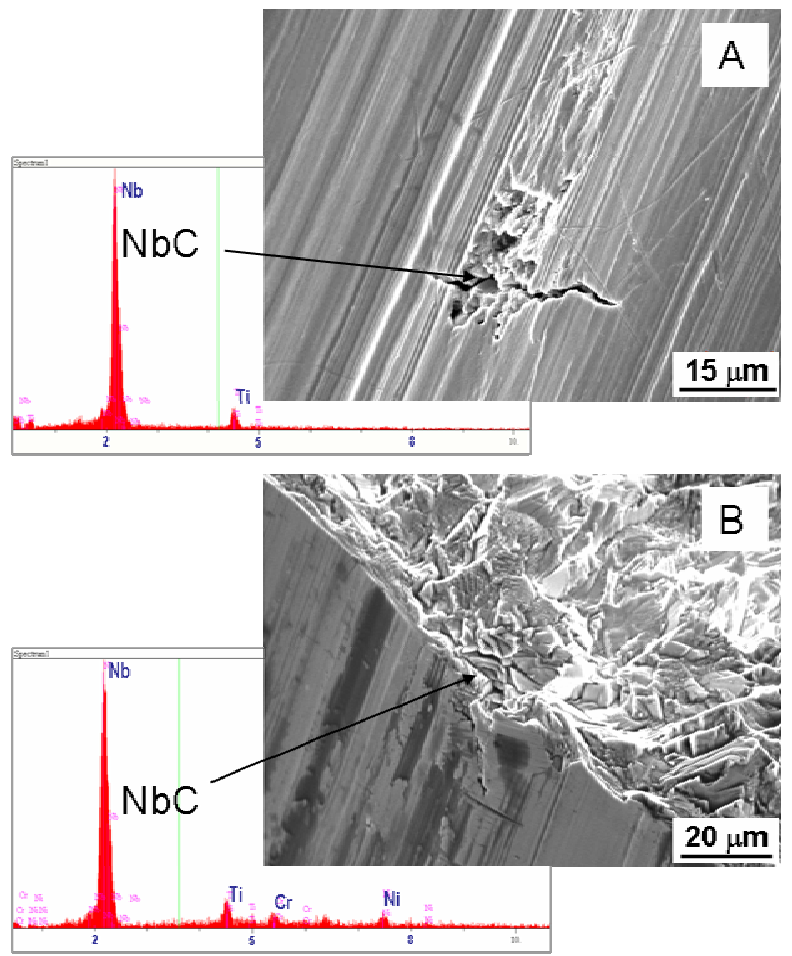

Figure 8. SEM of as-machined smooth LCF failure: (A) Example of secondary crack initiation, (B) Typical fracture initiation from NbC (560 K/1102 MPa).

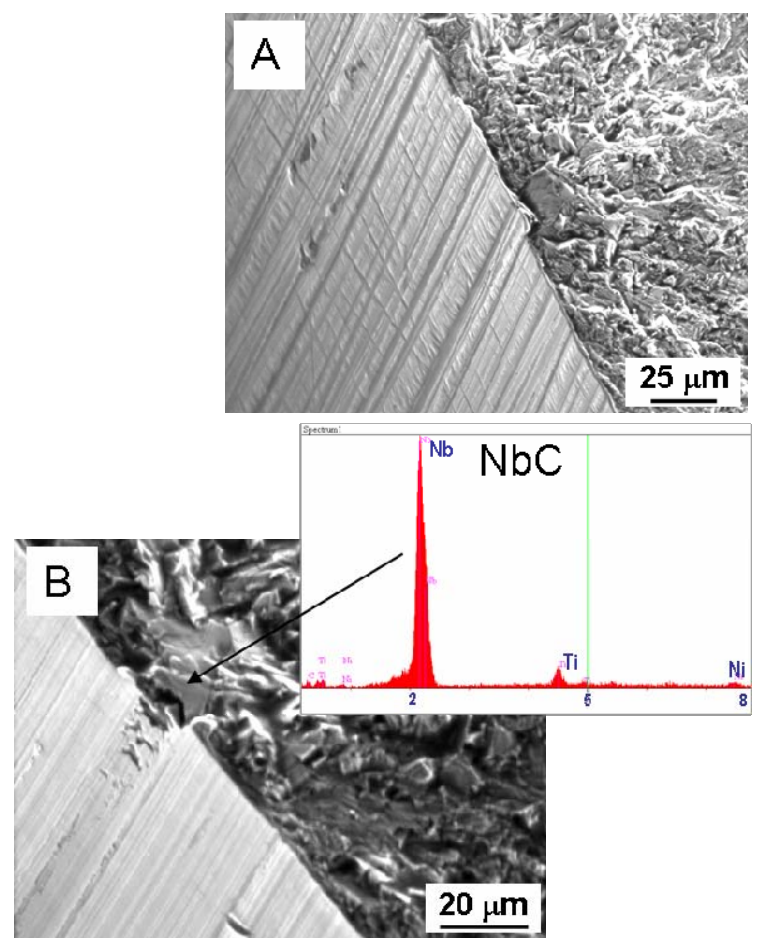

Figure 9. SEM of as-machined notched LCF failure: (A) Specimen surface near crack initiation site, and (B) Fracture initiation from surface NbC (560 K/595 MPa). 
Surface Observations Following Post-machine Processing and Effect on Low Cycle Fatigue Properties

Post-machine processing was examined, as noted before, for machined round holes only because there were a number of commercially available processes that could be easily utilized to process the SPB surface of the hole. The processes utilized were mechanical honing, extrude-hone, and jig-grinding per conditions stated earlier, and Fig. 10 illustrates the surface appearances from these processes. Note that all these processes removed material by

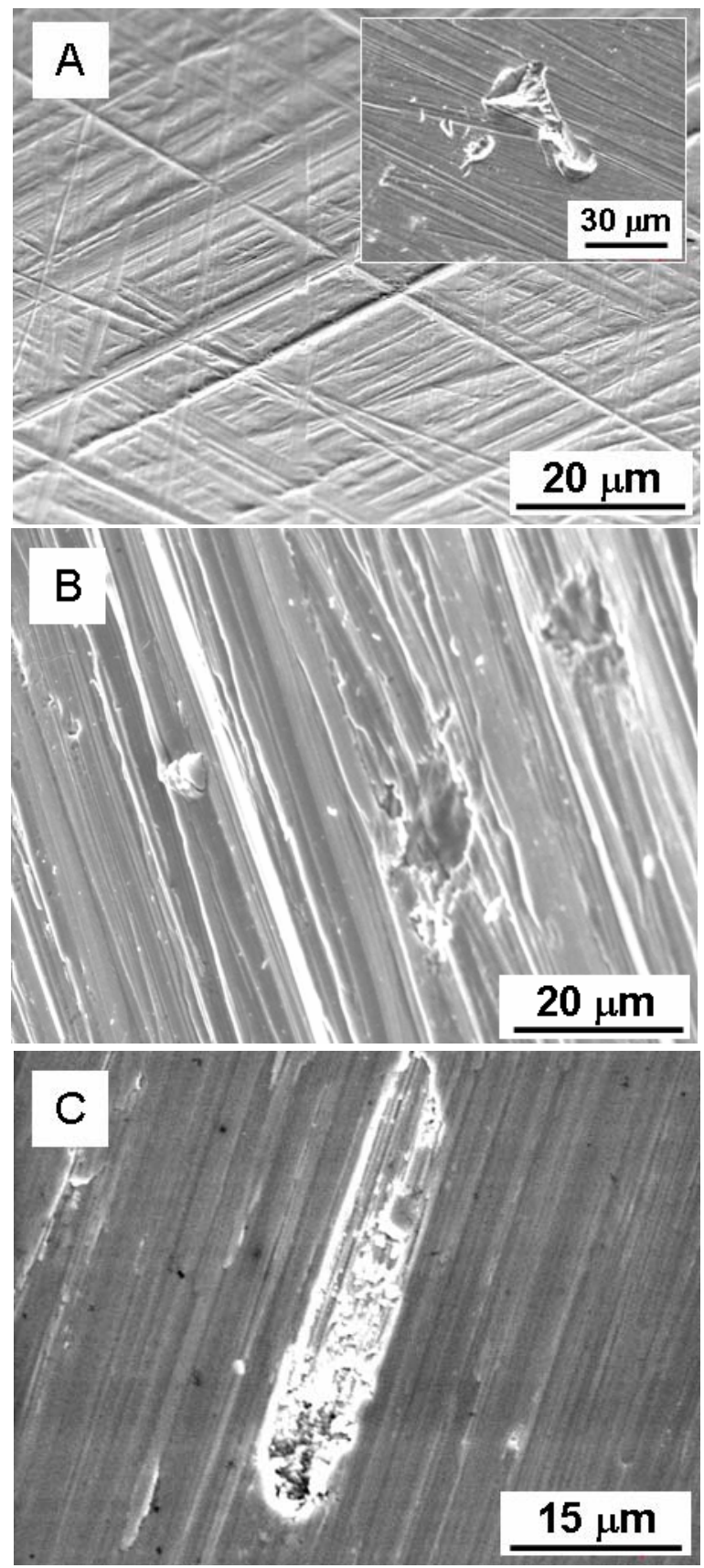

Figure 10. Examples of surface and $\mathrm{NbC}$ appearances after post-machine processing of round holes: (A) Mechanical honing, (B) Extrude honing, and (C) Jig grinding. a minimum amount of $25 \mu \mathrm{m}$ and thereby, removed the damaged layer on the surface from the SPB operation. Among these processes, the mechanical honing showed the least severe damage to the machined carbide. For example, the carbide in the inset of Fig. 10A was among the largest carbides (about $25 \mu \mathrm{m}$ ) but it was not as severely damaged or dragged as seen in other processes.

The notched LCF life with the central hole reconditioned by the above three processes is illustrated in Fig. 11. The LCF lives from the as-machined (SPB) notched specimens are included for comparison. All specimen failures initiated from carbides in these tests, and SEM micrographs illustrating these initiation sites are shown in Fig. 12. Referring to Fig. 11, the mechanical honing showed best LCF lives and all mechanically honed LCF tests exceeded SPB life. On a typical basis live improved by roughly $3 \mathrm{X}$. This was consistent with above surface observations in that mechanical honing probably caused least carbide damage and reduced the probability of badly damaged carbide. Nevertheless, this possibly resulted in the high scatter in data as seen in Fig. 11. The extrude-hone process showed improvement over SPB on a typical basis, and the jig grinding was essentially the same as SPB in terms of LCF life. . It should be noted that the SPB machining yields the best LCF capability on a probabilistic approach because of the tight scatter in the data, despite its lower typical life. However, the data in Fig. 11 clearly illustrated the potential of mechanical honing and extrude-hone processes in removing SPB damaged surface layer. Further effort is required to optimize the process parameters (such as feed rate and depth of cut) to reduce the scatter in the data. No such investigation was made in the present study.

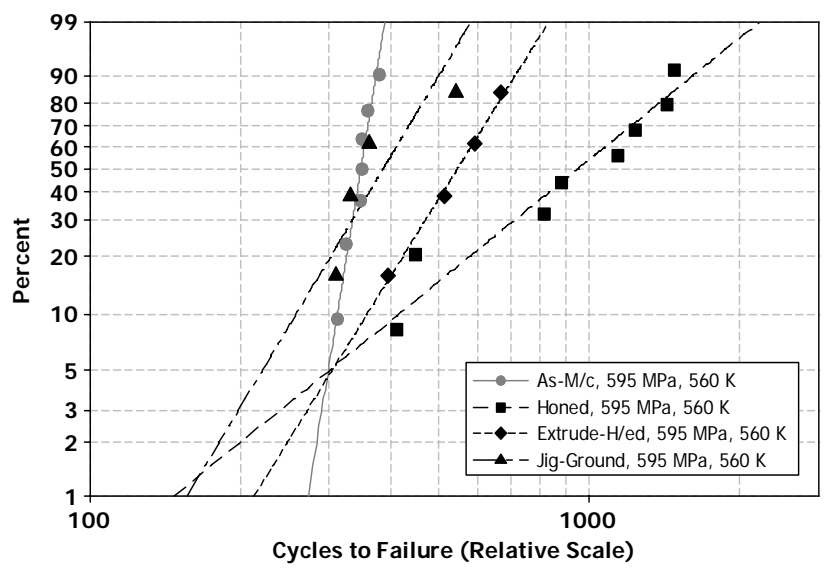

Figure 11. Weibull plot of notched LCF lives after postmachine processing in relation to as-machined (SPB) notched surface. 

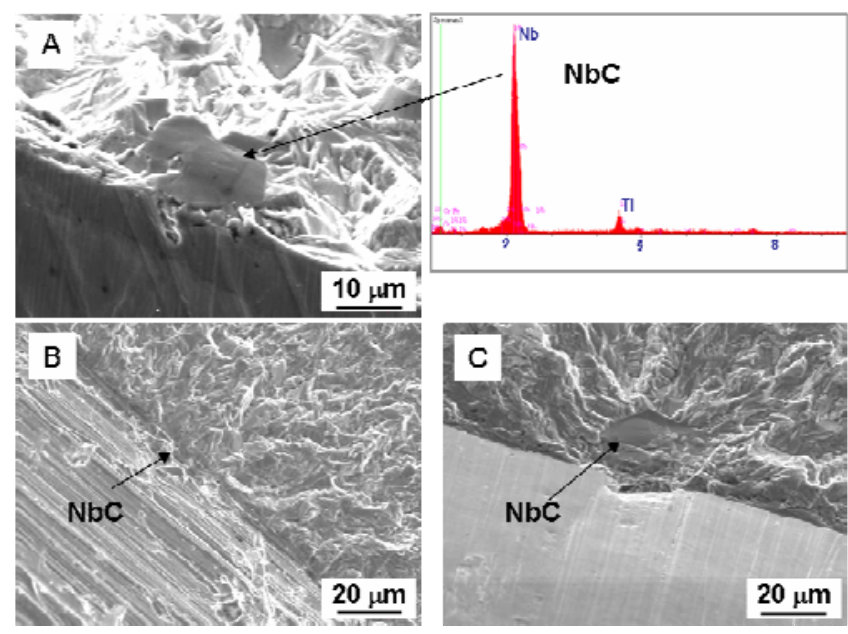

Figure 12. SEM of Notched LCF specimens following postmachine processing: (A) Mechanical honing, (B) Extrude honing, (C) Jig- grinding.

Surface Observations Following Introduction of Surface Residual Stresses and Effect on LCF Life

Surface residual stresses were introduced through shot-peening to an intensity of 4A on the as-machined (i.e., lathe-turned) flat surfaces of smooth LCF specimens. Figure 13 shows the residual stress profile with depth in the LCF specimen. A cross-section through the peened surface in also included in this figure. The shot peened surface essentially retained all surface carbides, including those previously cracked or damaged by the lathe turning operation. Following shot peening, the large carbides, as shown in Fig. 13, appeared highly fragmented.

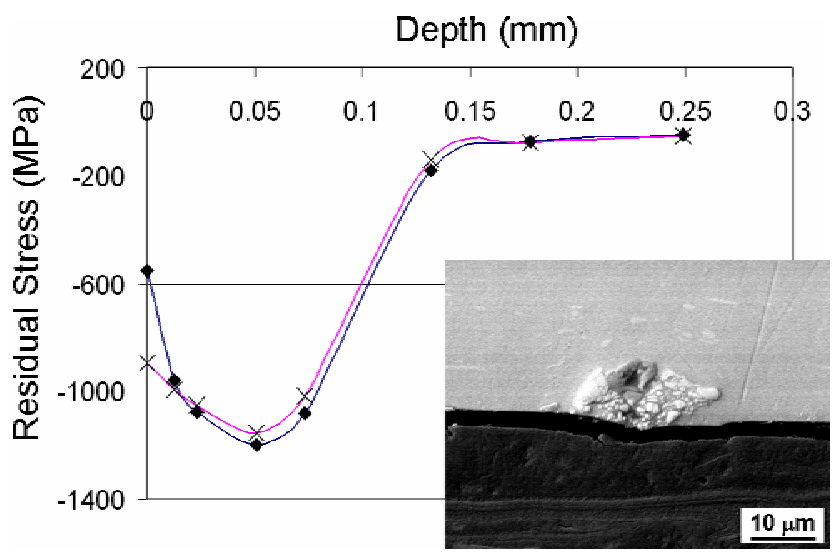

Figure 13. Residual stress pattern introduced by shot-peening and example of large carbide appearance at the surface following shot-peening.

Figure 14 shows smooth LCF life after shot-peening in relation to the as-machined specimens. The LCF life was recovered in these shot-peened specimens, and this can be attributed to the compressive residual stress at the surface that extended to $100 \mu \mathrm{m}$ with $-600 \mathrm{MPa}$ or more in magnitude. The compressive residual stress, therefore, protected the specimen from the machinedamaged layer. All shot peened LCF lives were shown with an arrow to the right in Fig. 14 to indicate that these flat LCF specimens (see Fig. 1A) fractured at the specimen shoulder and outside the gage section. The two groups of test data, A and B, were due to failures from surface carbides or internal grain facets, respectively, at the shoulder location.

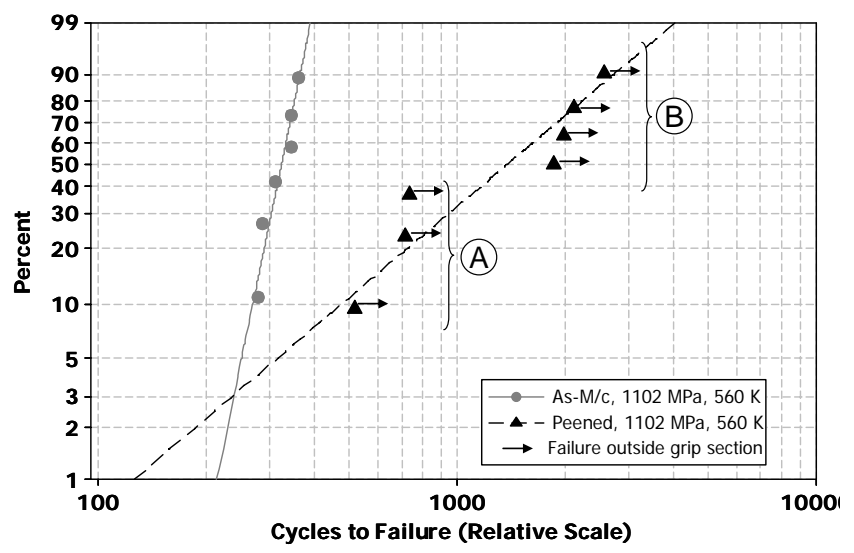

Figure 14. Weibull plot of smooth LCF lives after shot peening (4A) in relation to as-machined (lathe-turned) smooth surface. ' $A$ ' and ' $B$ ' refer to failures outside the specimen gage section, and from carbide and internal grain, respectively.

\section{Summary and Conclusions}

(1) The role of machining methods and their impact on surface integrity, smooth and notched LCF life of 'direct aged' IN718 forged disk was studied. Conventional machining practices, such as lathe-turning of surfaces and single point boring of holes, cracked or damaged the surface carbides considerably to impact the LCF life by factors of 3-15X depending on the test conditions. Cracked carbides were observed at both surface and subsurface levels, and were often restricted to a surface layer of $25 \mu \mathrm{m}$ or less.

(2) Full LCF life was possible in smooth specimens given a fine 400 and 600 grit polishing or media finishing where the damaged surface layer was removed. Some conventional post-machine processes for holes, such as mechanical honing, extrude hone and jig grinding, were studied. . Mechanical honing and extrude-hone showed potential as finishing processes to improve LCF life over as-machined surfaces, but will require future study with the process parameters optimized to prevent carbide damage. The statistically estimated minimum LCF capability of as-machined notched features is greater than post-machine treated notch features due to the tight scatter in the data.

(3) For flat, as-machined (lathe-turned) surfaces, shot peening was effective in protecting the surface layers containing cracked carbides under a deep compressive residual stress, and therefore, effectively recover LCF life 5-10X at minimum relative to an asmachined surface. 
The authors acknowledge support from Pratt \& Whitney in conducting this work, and Mr. Thomas E. Kenney and Mr. Mike W. Fox of Pratt \& Whitney for various phases of metallographic and property evaluation.

\section{References}

1. H.F. Merrick, "The Low Cycle Fatigue of Three Wrought Nickel-base Alloys,” Metall. Trans., 5A (1974), 891-897.

2. D. Fournier, and A. Pineau, "Low Cycle Fatigue Behavior of IN718 at $298 \mathrm{~K}$ and 823 K,” Metall. Trans., 8A (1977), 10951105.

3. N. Spath et al., "718 Superalloy Forging Simulation: A Way to Improve Process and Material Potentialities, Superalloys 718, 625, 706 and Derivatives 2001, ed. by E. A. Loria, (Warrendale, PA: TMS 2001), 173-183.

4. K. Kobayashi et al., "Grain Size Effect on High-temperature Fatigue Properties of Alloy 718,” Materials Letters, 59 (2005), 383-386.

5. Y. Ono et al., "High-cycle Fatigue Properties at Cryogenic Temperatures in IN718 Nickel-based Superalloy," Materials Trans., 45 (2004), 342-345.

6. P.R. Bhowal, and A.M. Wusatowska-Sarnek, "Carbides and Their Influence on Notched Low Cycle Fatigue Behavior of FineGrained IN718 Gas Turbine Disk Material," Superalloys 718, 625, 706 and Derivatives 2005, ed. by E. A. Loria, (Warrendale, PA: TMS 2005), 341-349.

7. R.S. Pawade et al., "An Investigation of Cutting Forces and Surface Damage in High-speed Turning of IN718,” Jour. Mater. Process. Technology, 192-193 (2007), 139-146.

8. A.R.C. Sharman, J.I. Hughes, and K. Ridgway, “An Analysis of the Residual Stresses Generated in IN718 when Turning,” Jour. Mater. Process. Technology, 173 (2006), 359-367.

9. T. Connolley, P.A.S. Reed, and M.J. Starink, "Short Crack Initiation and Growth at 600C in Notched Specimens of IN718," Mater. Sci. Eng., A340 (2003), 139-154.

10. T. Connolley, M.J. Starink, and P.A.S. Reed, "Effect of Broaching on High-Temperature Fatigue Behavior in Nothced Specimens of IN718," Metall. Materials Trans. 35A (2004), 771783.

11. Joseph R. Davis et al., eds., Metals Handbook, vol. 16 (Metals Park, OH: ASM International, 1989), 472-491.

12. Joseph R. Davis et al., eds., Metals Handbook, vol. 16 (Metals Park, OH: ASM International, 1989), 514-519.

13. Joseph R. Davis et al., eds., Metals Handbook, vol. 16 (Metals Park, OH: ASM International, 1989), 430-452.

14. E.E. Brown, and D.R. Muzyka, "Nickel-Iron Alloys," Superalloys II, ed. C.T. Sims et al., (New York, NY: John Wiley \& Sons, 1987), 165-188. 